\title{
Hypernatremic dehydration in exclusively breast fed neonates: a clinical study
}

\author{
Shivanagouda $\mathbf{J}^{1}$, Gayathri K², Roopa B.N ${ }^{3}$ \\ ${ }^{1}$ Dr. Shivanagouda J, Assistant Professor, ${ }^{2}$ Dr. Gayathri K, Post Graduate Student, ${ }^{3}$ Dr. Roopa B.N, Post Graduate \\ Student, all authors are affiliated with Department of Paediatrics, K. V. G. Medical College \& Hospital, Sullia. D. \\ $\mathrm{K}$, Karnataka, India.
}

Address for Correspondence: Dr. Gayathri K, Email id: gayathrikottuppallil@gmail.com

\begin{abstract}
Introduction: Neonatal hypernatremic dehydration is a very serious condition and there has been an increase in the incidence of hypernatremic dehydration in breast fed infants in the first week of life. Hypernatremia in neonates is found to be due to inadequate breast feeding or insufficient milk production. This study was conducted to look at the prevalence, clinical symptoms, signs and risk factors associated with hypernatremia in exclusively breast fed healthy neonates. Methodology: A Retrospective cross-sectional study conducted at KVG Medical College Sullia on 29 neonates with hypernatremic dehydration who were recruited during the period from June 2016 to April 2017. Healthy term neonates with birth weight more than $2.5 \mathrm{~kg}$, on exclusive breast feeding were considered for the study. Maternal problems regarding breast feeding were assessed. Serum sodium level more than $145 \mathrm{meq} / \mathrm{L}$ was considered as hypernatremia in our study. Results: Out of 32 neonates with hypernatremic dehydration, 29 were enrolled in the study as 3 were excluded because of low birth weight. Male babies were affected more than female babies with $16(55.17 \%)$ and $13(44.83 \%)$ respectively. The main presenting features were fever $(100 \%)$, poor feeding $(65.52 \%)$ and jaundice $(51.72 \%)$. The maximum number of babies who had hypernatremic dehydration presented in 46 hours to 60 hours of life (day 2-3). The results showed that the hours of life / day of presentation with hypernatremic dehydration has significant correlation with neonate's serum sodium concentration ( $\mathrm{P}$ value $<0.05$ ), indicating insufficient milk production in the mother during first few days. According to our study, babies born to primiparous women are more likely to be affected with hypernatraemic dehydration than multiparous women. Conclusion: It is recommended that dehydration and problems related can be considered as prime reason for fever during the first few days of life in low-risk term neonates. Special attention to antenatal care, postnatal care regarding early initiation of breast feeding and careful watch of neonates during the first week of life could decrease the incidence of neonatal hypernatremia.
\end{abstract}

Keywords: Neonate, Dehydration, Hypernatremia, Breast feeding, Exclusive, Serum sodium, Primiparous

\section{Introduction}

Breast feeding is universally considered to be the best and safest way of feeding neonates [1]. Many underlying factors can interfere with lactation and breast feeding and thus contribute to inadequate breast feeding and complications like hypernatremic dehydration [2]. Adequate breast milk depends on several interdependent processes- mammogenesis, lactogenesis, and galactopoeisis. It has been reported that healthy newborns even while on exclusively breast feeding developed Neonatal Hypernatremic

Manuscript received: $6^{\text {th }}$ August 2017

Reviewed: $16^{\text {th }}$ August 2017

Author Corrected: $25^{\text {th }}$ August 2017

Accepted for Publication: $30^{\text {th }}$ August 2017
Dehydration. The most important factor appears to be inadequate milk production. This condition is associated with cerebral oedema, intracranial haemorrhage, hydrocephalus and gangrene, thus carries an acute morbidity and mortality [2-4].

\section{Objectives}

1) To study the prevalence of neonatal hypernatremic dehydration in KVG Medical College, sullia.

2) To assess the presenting complaints and risk factors for hypernatremic dehydration. 


\section{Subjects and methodology}

Study design: A Retrospective cross - sectional study conducted from June 2016 to April 2017.

Setting: Department of Paediatrics, K.V.G Medical College, Sullia, Karnataka

\section{Inclusion criteria}

1) Healthy neonates - Gestational age (GA) $>36$ weeks, birth weight $>2.5 \mathrm{~kg}$, with normal neonatal adaptation, on exclusive breast feeding.

2) Healthy mothers who have no obstetric complication before or after delivery, given birth to a single baby

\section{Exclusion criteria}

1) Neonates with congenital malformation

2) Neonates with sucking problem

3) Birth asphyxia

4) Neonates with sepsis, birth weight $<2.5 \mathrm{~kg}$, GA $<36$ weeks

5) Babies on formula feeding

Participants: Neonates both inborn and outborn who presented to the department of paediatrics KVG Medical College, Sullia with hypernatremic dehydration were included in the study.

Source of Data: Records of neonates who where investigated and found to have hypernatremic dehydration during the time period from June 2016 to April 2017.

Study size: Total of 32 neonates were selected, out of which 3 were excluded because of low birth weight.

\section{Results}

The prevalence of hypernatremic dehydration among 562 deliveries from June 2016-April 2017 was found out to be $5.1 \%$. About $32(5.6 \%)$ neonates were diagnosed with hypernatremic dehydration \& 3 were excluded in view of low birth weight \& preterm. Hence a total of 29 (5.1\%) neonates were studied.

Out of 29, 13 (44.83\%) were females \& 16 (55.17\%) were males. Among these, $22(75.86 \%)$ neonates were born to primiparous women, $17(58.62 \%)$ delivered by normal vaginal delivery and $12(41.38 \%)$ by caesarean section.

The most common presenting complaints among those neonates was fever $100 \%(\mathrm{n}=29)$, followed by poor feeding $65.52 \%(n=19)$, jaundice $51.72 \%(n=15)$, weight loss $>10 \%$ was $44.8 \%(n=13)$, lethargy $20.69 \%(n=6)$, and seizure $1 \%(n=1)($ Fig I).
Methods: The records of neonates who were admitted with hypernatremic dehydration were analysed and it was found that total of 32 neonates were admitted and treated for hypernatremic dehydration during the period. Among the 32 neonates, 3 were excluded in view of low birth 28days of life), birth weight ( $\geq 2.5 \mathrm{~kg}$ ), weight loss $(>10 \%$ considered as significant), fever, lethargy, irritability, seizures, urination \& defecation per day $\&$ history of poor feeding were recorded. Maternal factors like age, parity, pregnancy problem, mode of delivery, breast feeding problems were analysed from the records. Axillary route was used for measuring body temperature (fever - temperature $>$ $37.8^{\circ} \mathrm{C}$ ). As the neonate presented with fever, lethargy and poor feeding, sepsis work up was done.

Laboratory investigations including complete blood count (CBC), Peripheral smear (PS), C-reactive protein (CRP), Random blood sugar (RBS) were done. CRP level $>10 \mathrm{mg} / \mathrm{L}$ was considered significant. Blood urea $(>30 \mathrm{mg} / \mathrm{dl})$ and Serum creatinine $(>0.8 \mathrm{mg} / \mathrm{dl})$ were considered significant suggesting prerenal failure as a part of dehydration. specific nomogram chart) were carried out in all babies who suffered from dehydration. Serum Sodium concentration $>145 \mathrm{meq} / \mathrm{L}$ was accepted as hypernatremia in our study.

Statistical analysis: The data obtained is analysed for statistical significance by using frequencies, percentage, tables, pie chart and by using SSPS version 22, values were expressed as mean+/-SD. Pearson correlation was used for studying correlation among various parameters with serum sodium concentration in which $\mathrm{P}$ value $<0.05$ was considered statistically significant. weight $(<2.5 \mathrm{~kg})$. Neonatal factors like age $(\leq$ Serum electrolytes, Serum Bilirubin (as per hour 


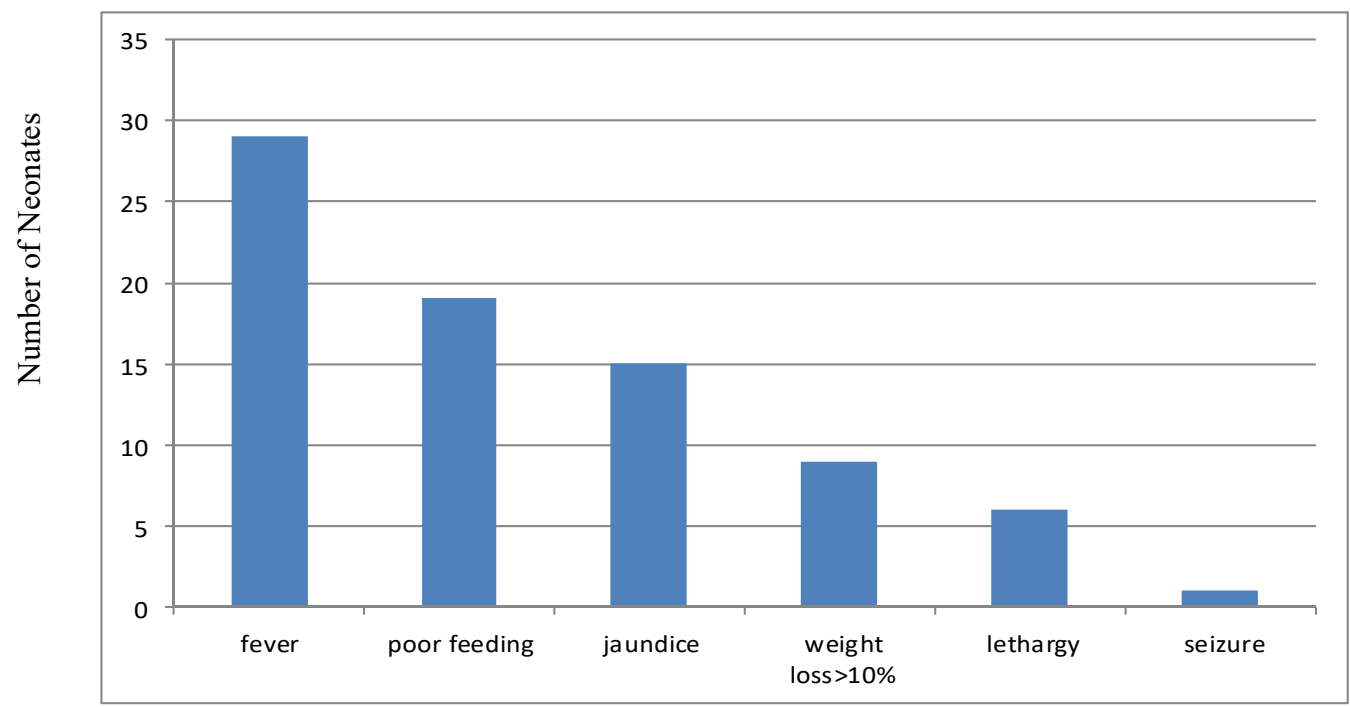

Fig-I: Clinical signs and symptoms (suggests fever as the most common presenting symptoms in neonates with hypernatremic dehydration)

Among 29 neonates, 10 (34.48\%) neonates presented in the first 26-45 hours of life and $18(62.07 \%)$ presented in 46 - 60 hours of life. Lab investigations revealed mean Haemoglobin (Hb) of 17.45 and mean Hematocrit (PCV) of 51.36. Among 29 neonates, $21(72.41 \%)$ had CRP values $<10 \mathrm{mg} / 1$ with a mean of 13 . Out of 29 neonates only 1 neonate had hypoglycaemia (RBS $-37 \mathrm{mg} / \mathrm{dl}$ ). Serum sodium concentrations studied were in range of 146-155 $\mathrm{meq} / 1$ in $15(51.72 \%)$ neonates, $156-165 \mathrm{meq} / 1$ in $14(48.28 \%)$ with a mean value of $155.44 \mathrm{meq} / \mathrm{l}$. Serum potassium concentrations were in range of 3.5-4.5 meq/1 in $17(58.62 \%)$ and $8(27.59 \%)$ had more than $5 \mathrm{meq} / 1$ with mean value of $4.49 \mathrm{meq} / 1$. Renal function tests were analysed as a part of dehydration leading to prerenal failure, $14(48.28 \%)$ had serum creatinine in range of $0.8-1 \mathrm{mg} / \mathrm{dl}$ with a mean serum creatinine of $0.86 \mathrm{mg} / \mathrm{dl} \mathrm{and}$ the mean blood urea value of $37.52 \mathrm{mg} / \mathrm{dl}$. Since $15(51.72 \%)$ neonates presented with jaundice, serum bilirubin was also done, which showed a mean value of $11.96 \mathrm{mg} / \mathrm{dl}$. (Table I)

Table-I: Hematological characteristics of cases.

\begin{tabular}{|c|c|c|c|c|c|}
\hline & Mean & Standard deviation & Minimum & Maximum & Median \\
\hline $\mathrm{Hb}$ & 17.45 & 2.15 & 13.4 & 23.7 & 17.2 \\
\hline $\mathrm{TC}$ & 22422.76 & 45873.68 & 8400 & 22800 & 13500 \\
\hline $\mathrm{PCV}$ & 51.36 & 7.46 & 39.2 & 68.8 & 48.6 \\
\hline $\mathrm{CRP}$ & 13 & 20.43 & 0.5 & 83.5 & 3.8 \\
\hline RBS & 70.65 & 13.07 & 37 & 94 & 70 \\
\hline Sodium & 155.44 & 4.05 & 149 & 165 & 155 \\
\hline Potassium & 4.49 & 0.52 & 3.2 & 5.2 & 4.4 \\
\hline Blood urea & 37.52 & 12.96 & 19 & 1.3 & 38 \\
\hline S. creatinine & 0.86 & 0.19 & 0.5 & 19.1 & 0.8 \\
\hline S. bilirubin & 11.96 & 3.30 & 7.4 & 10.2 & 11.5 \\
\hline S. calcium & 9.04 & 0.54 & 7.9 & & 9 \\
\hline
\end{tabular}

Pearson correlation was used for correlation of various parameters with serum sodium concentrations. As per Pearson correlation, only hours of life of presentation with hypernatremic dehydration has significant correlation with serum sodium concentration. The $\mathrm{P}$ value is 0.001812 ( $\mathrm{P}$ value $<0.05)$ (Table II). 
Table-II: Pearson correlation (as hours of life progress, increase in serum sodium level noted, suggesting decreased milk output in mother during the first 3-5 days of delivery).

\begin{tabular}{|c|c|c|}
\hline Correlation with sodium level & R value & P value \\
\hline Weight loss & 0.240765 & 0.20847 \\
\hline Hours of life & $\mathbf{0 . 5 5 4 2 6 9}$ & $\mathbf{0 . 0 0 1 8 1 2}^{*}$ \\
\hline Maternal age & -0.16908 & 0.380819 \\
\hline Gestational age & -0.21102 & 0.271892 \\
\hline Serum potassium & 0.321073 & 0.089533 \\
\hline PCV & -0.00919 & 0.96263 \\
\hline
\end{tabular}

Among maternal factors, 16 (55.17\%) were with less milk output, 4 (13.79\%) with short nipple, 3 (10.34\%) with poor feeding technique, $3(10.34 \%)$ with crack nipple, 1 with back pain, and $2(6.90 \%)$ were with unknown cause (Fig II)

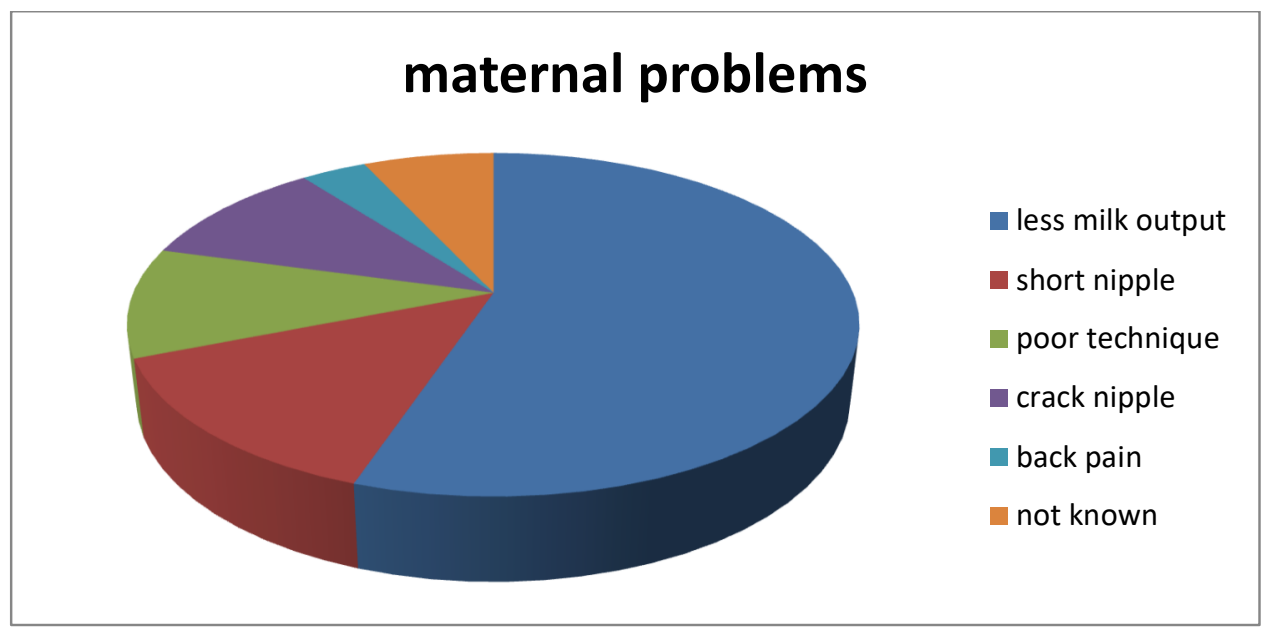

Fig-II: Maternal problems as a risk factor for neonatal hypernatremic dehydration (decrease milk output in the mother during first few days of delivery holds the highest percentage as the risk factor, suggesting either lactation failure or reduction in feeding frequency leading to increase in breast milk sodium)

\section{Discussion}

Neonatal Hypernatremic dehydration is a potentially devastating condition. It has been found that hypernatremic dehydration is increasing in exclusively breast fed neonates [4].

In our study, maximum number of neonates 18 $(62.02 \%)$, who were exclusively breast fed, presented with hypernatremic dehydration in the $2^{\text {nd }}$ $-3^{\text {rd }}$ day of life. The most common maternal problem associated was decreased milk output mainly due to ineffective galactopoiesis. Adequate breast milk intake depends on normal mammogenesis, lactogenesis, galactopoiesis, as well as effective milk delivery to the neonate. The effective milk delivery depends on effective breast feeding technique, combined with an intact milk ejection reflex. The volume of human milk consumed by a neonate depends on the frequency and duration of feeds and pattern of breast use. Normally it's usually on demand every $2-3^{\text {rd }}$ hours, with a range of $10-70 \mathrm{ml}$ per feed over a period of 520 minutes [5]

Hypernatremia may be associated with decrease in fluid intake, excessive fluid loss or excessive sodium intake [3]. In 1949, Macy established mean sodium content of colostrums in the first 5 days is $22 \mathrm{mmol} / \mathrm{l}$, transitional milk from day 5 to day 10 is $13 \mathrm{mmol} / 1$ and of mature milk after 15 days is $7 \mathrm{mmol} / 1$. It was showed that higher levels of sodium in breast milk are associated with lactation failure, and a reduction in feeding frequency is associated with a marked rise in milk sodium concentrations $[3,7]$. It has showed that insufficient milk production 
is the most important factor in the induction of neonatal hypernatremic dehydration. Lactogenesis stage II, the onset of sufficient milk production, occurs during the first 4 days after delivery $[6,7]$

Thus it suggests that the most common cause of excessive weight loss and hypernatremia is inadequate breast milk intake as it is in our case. It has been demonstrated that if women fail to establish good breast-feeding, the normal physiological decrease in breast milk sodium concentration does not occur. However, when relactation is successfully established sodium returns to normal limits $[6,8,9]$.

Since the poorly fed infant is not able to obtain high sodium content from a low volume of milk in the first few days of life, hypernatremia is because of water deprivation and a secondary accumulation of sodium in an attempt to maintain circulatory volume occurs [6].

About $22(75.86 \%)$ were primiparous women in this study, and this has been reported as one of the most important risk factor for neonatal hypernatremic dehydration. This indicates that monitoring the mother and baby in the first week of life or successful establishment of breast feeding is essential. The mothers should receive practical advice in breast feeding technique [10].

Along with insufficient milk production during the first few days after delivery, other maternal problems also contribute towards decreased milk intake such as short nipple, crack nipple, as in our study 7 mothers were having which contributes to about $24.14 \%$.

Out of 29 neonates less than half $13(44.83 \%)$ of neonates had weight loss $>10 \%$. This is because infants with hypernatremic dehydration have better preserved extracellular volume and therefore lesspronounced clinical signs of dehydration $[11,12]$. In our study there was no significant correlation between weight loss and serum sodium concentrations ( $\mathrm{P}$ value $>0.05$ ).

The association of hypernatremia with hyperbilirubinema, which occurred in 15 (51.72\%) of our neonates, might contribute to long term sequalae as hypernatremia causes impairment of blood brain barrier and hence bilirubin diffuses into the brain causing bilirubin encephalopathy $[2,6]$. Hypernatremia and hyperbilirubinemia cause central nervous system depression among infants with lethargy and poor suck. These factors can lead to a cycle of worsening dehydration, jaundice, and hypernatremia, which in combination can lead to brain injury [11]. But in our study no such complication occurred.

These neonates with hypernatremic dehydration with serum sodium in the range of $145-155 \mathrm{meq} / 1$ were adviced to continue breast feeding. Formula feeds were given for 3-4 days in view of less milk output in mother. Neonates with serum sodium level $>155 \mathrm{meq} / \mathrm{L}$ were treated with intravenous fluid correction.

An increased awareness among health professionals is required so that this potentially devastating condition can be prevented by putting an emphasis on exclusive lactation with recommended postdischarge follow-up to assess the health status of both mother and baby. Moreover, all mothers should be taught the skills of breastfeeding.

Limitation of the study: Lack of mother's breast milk sodium level as this was a retrospective study.

\section{Conclusion}

Neonatal hypernatremic dehydration, a potentially lethal condition, can be prevented by proper antenatal care, proper initiation of breast feeding after delivery and careful follow-up of feeding and weight gain in the neonate. Prompt intervention should be carried out if problems with breast such as short nipple, crack nipple, poor technique of feeding. These will help promote successful breast feeding.

From the study it is recommended that dehydration and problems related can be considered as prime reason for fever during the first few days of life in low-risk term neonates.

Almost more than half of the primi mothers were unaware of the correct feeding technique which emphasizes the need of regular educational programs and workshop in prenatal period.

Acknowledgement: We thank our Community Medicine Department for guiding us in doing statistical analysis. 
Abbreviations used: GA- Gestational Age, CBCcomplete blood count, PS- Peripheral Smear, CRPC-reactive protein, $\mathrm{Hb}$ - haemoglobin, TC- total count, PCV- Hematocrit, GRBS- Random blood sugar.

Funding: Nil, Conflict of interest: None initiated, Perission from IRB: Yes

\section{References}

1. Boskabadi H, Ramazanzadeh M, Zakerihamidi M, Rezagholizade Omran F. Risk factors of breast problems in mothers and its effects on newborns. Iran Red Crescent Med J. 2014 Jun;16(6):e8582. doi: 10.5812/ircmj.8582. Epub 2014 Jun 5.

2. Boskabadi H, Maamouri G, Ebrahimi M, Ghayour-Mobarhan M, Esmaeily H, Sahebkar A, et al. Neonatal hypernatremia and dehydration in infants receiving inadequate breastfeeding. Asia Pac J Clin Nutr.2010;19(3):301-7

3. Mujawar NS, Jaiswal AN. Hypernatremia in the neonate: Neonatal hypernatremia and hypernatremic dehydration in neonates receiving exclusive breastfeeding. Indian J Crit Care Med 2017;21:30-3. DOI: 10.4103/0972-5229.198323.

4. Livingstone V H, Willis C E, Abdel-Wareth L O et al. Neonatal hypernatremic dehydration associated with breast-feeding malnutrition : a retrospective survey. Cannadian Med Asso J.2000; 162 (5):647-52.

5. Bhat SR, Lewis P, David A, Liza SM. Dehydration and hypernatremia in breast-fed term healthy neonates. Indian J Pediatr. 2006 Jan;73 (1):39-41.
6. Caglar MK, Ozer I, Altugan FS. Risk factors for excess weight loss and hypernatremia in exclusively breast-fed infants. Braz J Med Biol Res. 2006 Apr; 39 (4):539-44. Epub 2006 Apr 3.

7. Neville MC, Allen JC, Archer PC, Casey CE, Seacat J, Keller RP, Lutes V, Rasbach J, Neifert M. Studies in human lactation: milk volume and nutrient composition during weaning and lactogenesis. Am J Clin Nutr. 1991 Jul; 54(1): 81-92.

8. Morton JA. The clinical usefulness of breast milk sodium in the assessment of lactogenesis. Pediatrics. 1994 May;93(5):802-6.

9. Sofer S, Ben-Ezer D \& Dagan R. Early severe dehydration in young breast-fed newborn infants. Israel Journal of Medical Sciences.1993;29(2-3): 85-89.

10. Scott JX, Raghunath,Gnananayagam JE, Simon A. Neonatal hypernatremic dehydration and malnutrition associated with inadequate breastfeeding and elevated breast milk sodium. J Indian Med Assoc. 2003;101(5):318-21.

11. Moritz M L, Manole D M, Bogen L D et al.Breastfeeding-Associated Hypernatremia: Are We Missing the Diagnosis?.PEDIATRICS 2005;116(3): e343-47. DOI:10.1542/peds.2004-2647

12. Manganaro R, Mami C, Marrone T, Marseglia L, Gemelli M. Incidence of dehydration and hypernatremia in exclusively breast-fed infants. J Pediatr. 2001; 139 (5): 673-5. DOI:10.1067/ 2001. 118880 .

\section{How to cite this article?}

Shivanagouda J, Gayathri K, Roopa B.N. Hypernatremic dehydration in exclusively breast fed neonates: a clinical study. J PediatrRes. 2017;4(08):525-530.doi:10. 17511/ijpr.2017.i08.05. 